\title{
Peran money attitudes terhadap financial well-being dengan financial stress sebagai mediator pada mahasiswa rantau di Surabaya
}

Honey Wahyuni Sugiharto Elgeka ${ }^{*}$, Gabriella Querry²

1,2Fakultas Psikologi, Universitas Surabaya, Indonesia

\begin{tabular}{l}
\hline Info Artikel \\
\hline Sejarah Artikel: \\
Diterima \\
OI Oktober 2020 \\
Direview \\
OI Oktober 2020 \\
Disetujui \\
I5 Desember 2020 \\
Dipublikasikan \\
I5 Januari 202 I \\
\hline Keywords: \\
Money attitudes, \\
financial well-being, \\
financial stress, \\
mahasiswa rantau
\end{tabular}

\section{Abstrak}

Objektif: Pengelolaan keuangan yang baik pada kehidupan mahasiswa rantau akan dapat berdampak pada financial well-being. Hipotesis dari penelitian ini adalah financial stress dapat berperan sebagai mediator pada hubungan antara money attitudes terhadap financial well-being.

Metode: Responden pada penelitian ini adalah mahasiswa rantau yang tinggal di Surabaya berusia 17-22 tahun dan berjumlah 267 responden. Teknik pengambilan sampel menggunakan accidental sampling. Metode analisis data menggunakan process hayes model 4 .

Temuan: Hasil penelitian ini menjelaskan bahwa financial stress dapat berperan sebagai mediator (parsial) dengan nilai negatif, dimana aspek power prestige dan distrust dalam money attitudes berhubungan positif dengan financial well-being.

Kesimpulan: Hal ini menjelaskan bahwa mahasiswa rantau menganggap uang sebagai simbol kesuksesan, dapat memberikan kesan yang baik bagi orang lain, dan menimbulkan financial well-being serta tidak mengalami financial stress. Selain itu, kondisi ini akan sangat berdampak pada nilai akademik dan kesehatan mental para mahasiswa rantau jika mereka salah dalam mengelola keuangannya.

\section{The role of money attitudes on financial well-being with} financial stress as a mediator on mahasiswa rantau's life in Surabaya

Objectives: Good financial management on "mahasiswa rantau"'s life will have an impact on their financial well-being. The hypothesis of this research is financial stress can act as a mediator on the relationship of money attitudes and financial well-being.

Method: Respondents in this research were "mahasiswa rantau" that live in Surabaya age 17-22 years and the total of respondents were 267 people. The sampling technique used accidental sampling. Methods of data analysis using PROCESS HAYES model 4.

Findings: The result found that financial stress has an indirect effect on the negative correlation, whereas power prestige and distrust money attitudes, and financial well-being have a positive correlation.

Conclusions: It means that "mahasiswa rantau" thought that money is a symbol of success, impress others, and build financial well-being also financial stress does not exist. Besides that, this situation will give an impact on academic performance and mental health if they are wrong in managing finances.

\footnotetext{
*Alamat korespondensi:

Universitas Surabaya, Jl. Raya Kalirungkut, Surabaya, Jawa Timur, 60293, Indonesia

honeywahyuni@staff.ubaya.ac.id
} 


\section{Pendahuluan}

Tuntutan kehidupan yang semakin berat membuat beberapa anak mulai memikirkan untuk melanjutkan pendidikan ke jenjang yang lebih tinggi, yaitu perguruan tinggi (baik D3 ataupun SI). Tak dapat dipungkiri bahwa dari berbagai pulau di Indonesia, universitas yang ada di Pulau Jawa ternyata masih menjadi pilihan utama. Hal ini ditunjukkan berdasarkan data yang ditampilkan oleh PDDIKTI (20I8) diketahui ada 4.670 universitas di Indonesia dimana 1.566 universitas (47.56\%) berada di Pulau Jawa, selain itu ternyata terdapat 904.492 mahasiswa baru (61.44\%) yang terdaftar di universitas tersebut. Tidak menutup kemungkinan bahwa beberapa diantara mahasiswa baru tersebut adalah mahasiswa rantau. Di saat mereka memutuskan untuk menempuh pendidikan tinggi di Pulau Jawa, tentu mereka harus tinggal terpisah dari orang tua dan memilih tinggal sendiri di kos, apartment, ataupun tinggal di rumah kerabat. Tidak hanya itu, para mahasiswa rantau ini pun mulai dituntut untuk belajar mengatur hidupnya sendiri, khususnya pada pengelolaan keuangan. Secara disadari ataupun tidak, mahasiswa rantau diajak untuk harus mampu hidup mandiri dan mampu mengelola uang dengan bijak.

Nidar \& Bestari (20I2) dalam penelitiannya mengatakan bahwa setiap individu harus belajar dan mengerti bagaimana melakukan financial management; begitu juga dengan mahasiswa rantau. Wulandari \& Hakim (20I5) juga menyatakan bahwa setiap individu harus mampu untuk mengetahui dan mengerti financial management secara pribadi yang dapat disebut dengan "melek" akan keuangan pribadi. Di kala individu mampu mengelola keuangan dengan baik dan mengejar kepuasan hidup, tentu diharapkan agar mereka mampu meningkatkan financial well-being (Akben-Selcuk, 20 I5; Shim, Barber, Card, Xiao, \& Serido, 20 I0). Hal penting yang perlu diperhatikan untuk mencapai financial well-being adalah kemampuan untuk memiliki rasa aman pada kondisi keuangan dimasa yang akan datang (Yolanda \& Rembulan, 20 I 7). Menurut Sabri \& Zakaria (20I5), individu yang belum mampu memenuhi kebutuhan keuangannya atau mengalami financial hardship dianggap belum memiliki financial well-being.

Hal ini pun kemungkinan besar juga dialami oleh mahasiswa rantau, khususnya di saat mereka salah dalam mengelola keuangannya, yaitu dengan menggunakan kartu kredit secara berlebihan atau tidak adanya perencanaan keuangan yang baik (Rasyid, 20I2). Godaan untuk hidup konsumtif dengan melakukan pembelian pada barang-barang yang kurang dibutuhkan seringkali membuat individu mengalami financial hardship, tak terlepas yang dialami oleh mahasiswa rantau (Herlindawati, 20I5). Tidak hanya itu, jika individu tidak belajar untuk membuat budget dan rencana keuangan, maka financial security tidak akan tercapai dan financial well-being pun akan mengalami hambatan (Sabri \& Zakaria, 20I5). Sebelum melakukan survey untuk penelitian, maka di bulan April 2019 dilakukan survey awal pada 2 I mahasiswa rantau di salah satu universitas di Surabaya. Hal ini ditujukan untuk mengetahui tingkat financial well-being para mahasiswa rantau di Surabaya. Hasil dari survey awal itu menunjukkan bahwa $66.7 \%$ mahasiswa rantau belum merasa sejahtera secara keuangan. Beberapa hal yang membuat para mahasiswa rantau ini tidak sejahtera adalah mereka secara keuangan masih bergantung penuh terhadap orang tua, memiliki sifat boros atau belum mampu mengelola uang dengan baik, serta adanya kecemasan akan masa depan (menafkahi keluarga).

Selain itu, Otoritas Jasa Keuangan (OJK) di tahun 2019 menjelaskan bahwa ada peningkatan kemampuan dalam indeks financial literacy (kemampuan memahami keuangan) pada masyarakat Indonesia sebesar $8.33 \%$, dimana posisi indeks financial literacy masyarakat Indonesia saat ini berada di angka 38.03\% (Prabowo, 2019). Meskipun data dari OJK itu menyatakan adanya peningkatan financial literacy di penduduk Indonesia, namun pada kenyataannya masih ditemukan ada beberapa masyarakat yang mengalami financial hardship, salah satunya adalah mahasiswa rantau. Fenomena yang terjadi pada mahasiswa rantau ini menggambarkan salah satu contoh kondisi yang dialami masyarakat Indonesia, dimana masih cukup banyak masyarakat yang belum memahami betul makna dari financial well-being.

Financial well-being sendiri dijelaskan sebagai suatu keadaan dimana individu mampu secara penuh memenuhi kewajiban keuangan saat ini dan yang sedang berlangsung, memiliki rasa aman pada keuangan di masa yang akan datang, serta mampu membuat pilihan yang akan memberikan 
kenikmatan hidup (Cfpb, 20I5). Joo (2008) menjelaskan bahwa financial well-being digambarkan sebagai sebuah perasaan yang sehat secara keuangan, bahagia, dan bebas dari segala kecemasan; hal ini didapatkan dari penilaian subjektif setiap individu terkait keadaan keuangannya. Financial well-being merupakan konsep baru dalam keuangan rumah tangga ataupun konsumen, dimana teori ini didasari dari teori subjective well-being, tidak hanya itu, teori terkait financial well-being ini masih terus diteliti dari dua bidang studi, yaitu psikologi dan ekonomi (Collins \& Urban, 2020; Guven, 20I2). Apabila individu ingin mendefinisikan tentang well-being, tentu konteks keuangan dan pengelolaan uang tidak dapat lepas darinya, hal inilah yang membuat setiap individu memerlukan adanya financial well-being.

Selain itu, Shim et al. (2010) pada penelitiannya juga menjelaskan bahwa financial well-being akan berkaitan dengan keseluruhan life satisfaction, psychological well-being, kondisi kesehatan, dan juga academic performance. Meskipun demikian, perlu dipahami bahwa agar individu dapat memperoleh financial well-being ternyata peran orang tua akan sangat berdampak besar, hal ini dapat dipahami dari bagaimana orang tua mengajarkan makna uang pada anak-anaknya, menanamkan ekspektasi dan nilainilai diri, serta secara aktif berkontribusi pada persepsi anak terkait kontrol perilaku.

Beberapa penelitian terdahulu menganalisa financial well-being berdasarkan beberapa perspektif seperti kepribadian, financial management, materialisme, dan self-control (Donnelly, lyer, \& Howell, 2012; Strömbäck, Lind, Skagerlund, Västfjäll, \& Tinghög, 2017). Sabri \& Zakaria (2015) pada penelitiannya menjelaskan beberapa hal yang memengaruhi terbentuknya financial well-being yaitu financial literacy, financial capability, financial strain/stress, dan money attitude. Sehingga pada penelitian ini financial well-being dianalisa dari perspektif money attitudes dan financial stress. Menurut Beutler \& Gudmunson (20I2) pemahaman tentang uang secara psikologis dimulai dari aliran psikoanalisa dan behavioristik. Pada aliran psikoanalisa, uang dipahami berdasarkan 'teori anal' yang dipopulerkan oleh Freud, yaitu bagaimana individu memiliki pengalaman awal terkait uang hingga mereka pada akhirnya menentukan sikap terhadap uang tersebut. Sedangkan pada aliran behavioristik, uang biasanya digunakan sebagai bentuk penguatan dari beberapa perilaku, seperti yang biasa dikondisikan pada hewan dan manusia.

Money attitudes diharapkan dapat menggambarkan terbentuknya financial well-being individu. Hayhoe et al. (20I2); Kowalczyk \& Chudzian (20I5); von Stumm, Fenton O'Creevy, \& Furnham (20I3) menjelaskan money attitudes sebagai cara individu memandang, menilai, memperlakukan uang, dan juga sebagai motivator untuk membentuk perilaku membeli. Money attitudes terbagi menjadi empat aspek, yaitu power-prestige (uang digambarkan sebagai simbol kesuksesan dan digunakan untuk memberikan kesan serta mempengaruhi orang lain), retention time (individu akan sangat berhati-hati dalam perilaku berbelanja dan sangat teliti untuk membuat rencana keuangan sehingga akan menimbulkan rasa aman), distrust (adanya rasa curiga dan ragu-ragu pada situasi yang melibatkan uang), dan anxiety (mengalami kesulitan dan kekhawatiran yang berlebihan terkait masalah-masalah uang)(Chi \& Banerjee, 20I3).

Money attitudes akan berhubungan dengan life satisfaction dan akan menentukan bagaimana individu memandang uang tersebut. Apabila individu dirasa begitu mencintai uangnya, mereka cenderungakan lebih puas. Hal ini terjadi dikarenakan individu merasa mampu memenuhi kebutuhan materinya. Berdasarkan penelitian Campara, Vieira, \& Potrich (2017); Sabri \& Zakaria (20I5) diketahui bahwa persepsi individu terkait subjective well-being akan sangat dipengaruhi oleh aspirasi hidupnya, yaitu uang. Di saat individu memiliki uang berlimpah, mereka akan merasa bahagia dibandingkan sebaliknya. Bagi individu uang digambarkan sebagai simbol dari status hidup serta dapat memberikan kesan (impression) yang baik tentang dirinya (Elgeka, Ma, Secapramana, \& Yudiarso, 20I9; Khare, 20I5).

Di saat mahasiswa rantau harus mengelola keuangannya, terkadang mereka jatuh pada penyalahgunaan kartu kredit ataupun belanja secara berlebihan. Secara umum, pemerintah Indonesia belum memiliki data yang konkrit untuk menghitung berapa jumlah mahasiswa rantau yang mengalami masalah keuangan, baik disebabkan oleh karena dukungan keuangan dari orang tua yang kurang memadai ataupun faktor kesalahan dalam financial management. Namun masalah keuangan ini akan berdampak pada terbentuknya financial stress yang dapat mempengaruhi nilai akademik, kesehatan secara fisik ataupun mental individu (Northern, O'Brien, \& Goetz, 2010). 
Menurut Mokhtar \& Husniyah (2017); Vosloo, Fouche, \& Barnard (20I4) financial stress dipahami sebagai persepsi setiap individu terhadap keuangan pribadinya. Oleh karena itu, setiap individu harus memahami secara benar apa penyebab financial stress itu, apakah karena ada financial behavior yang buruk atau hal lainnya (Sina \& Raturomon, 20 I5). Pada penelitian Sabri \& Zakaria (20I5) diketahui bahwa financial stress dapat berperan sebagai mediator dan memiliki korelasi negatif dengan financial well-being. Selain itu, financial stress akan berdampak pada financial satisfaction. Meskipun demikian, ternyata penelitian terkait financial stress yang akan berdampak pada financial well-being masih belum banyak diteliti.

Berdasarkan fenomena yang terjadi di mahasiswa rantau di atas, maka penelitian ini dilakukan untuk menguji dan menjelaskan hubungan antara money attitudes dan financial well-being dengan menggunakan financial stress sebagai mediator. Melalui penelitian ini diharapkan bisa membantu mahasiswa rantau untuk mengenali sikap mereka terhadap uang dan menghindari financial stress, sehingga mahasiswa rantau bisa meraih financial well-being di dalam hidup sehari-hari serta tidak mengalami gangguan pada prestasi akademik ataupun kesehatan mentalnya. Hipotesis pada penelitian ini adalah financial stress dapat menjadi mediator antara money attitudes dengan financial well-being.

\section{Metode}

Pada penelitian ini metode survey kuantitatif digunakan untuk menganalisa 267 responden yang berusia 17-22 tahun. Pengumpulan data pada penelitian ini dilakukan sejak 25 September - I8 Oktober 2019. Responden pada penelitian ini adalah mahasiswa aktif yang ada di Universitas Surabaya dan dari berbagai fakultas (Fakultas Farmasi, Hukum, Ekonomi, Psikologi, Teknik, Industri Kreatif, dan Kedokteran). Teknik accidental sampling digunakan sebagai teknik pengambilan datanya, yaitu mahasiswa yang secara insidental bertemu dengan peneliti dan memiliki kriteria yang cocok akan dipilih untuk menjadi responden. Metode analisis pada penelitian ini menggunakan PROCESS HAYES model 4.

Alat ukur pada financial well-being diadaptasi dari Consumer Financial Protection Bureau (Cfpb, 20 I 5) tentang Financial Well-Being Scale. Skala ini terdiri dari 10 aitem dengan menggunakan 5 skala. Money Attitude Scale (MAS) diadaptasi dari Yamauchi \& Templer (1982) digunakan untuk mengukur money attitudes. Money Attitude Scale dapat tetap digunakan pada penelitian ini karena setiap dimensi yang terkandung didalamnya dapat mewakili factor sikap yang mencerminkan sikap mahasiswa terhadap uang, selain itu pembuatan alat ukur ini juga ditujukan bagi mahasiswa. Alat ukur ini terdiri dari 29 aitem dengan menggunakan 7 skala Likert $(I=$ tidak pernah hingga $7=$ selalu $)$. Alat ukur yang terakhir adalah Financial Strain Survey yang diadaptasi dari Sabri \& Zakaria (2015) dengan menggunakan 3 aitem yang terdiri dari 5 skala Likert ( $I=$ tidak pernah hingga $5=$ selalu) untuk mengukur financial stress.

Penelitian ini menggunakan satu variabel yang akan menjadi mediator, yaitu financial stress, sehingga model konseptual penelitian yang dilakukan dijelaskan pada Gambar I: 


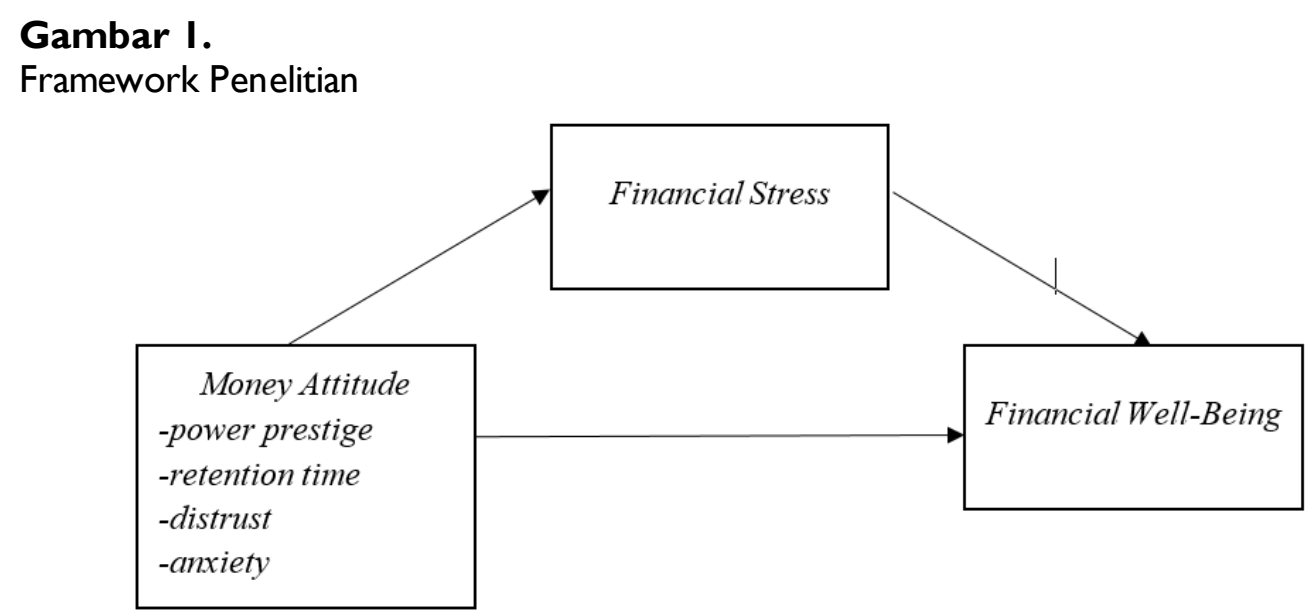

\section{Hasil}

$77.2 \%$ (206 orang) dari responden penelitian ini adalah perempuan, 33.3\% (89 orang) berada pada usia 2 I tahun, $22.8 \%$ (6 I orang) berusia 20 tahun, I 6.9\% (45 orang) berusia I 9 tahun. Berdasarkan data mahasiswa rantau yang ada di Universitas Surabaya diperoleh 135 orang (50.6\%) berasal dari Pulau Jawa di luar kota Surabaya, 52 orang (19.5\%) dari Pulau Kalimantan, 27 orang (10.1\%) dari Pulau Sulawesi, 23 orang (8.6\%) dari Pulau Bali. Pengujian reliabilitas dilakukan pada ketiga variabel yang digunakan, yaitu financial well-being dengan nilai $\alpha=.805$ (dengan menggugurkan 4 aitem unfavorable), money attitudes dengan nilai $\alpha=.85 \mathrm{I}$, financial stress dengan nilai $\alpha=.872$ (menggugurkan I aitem).

Sebelum menguji peran mediator, maka dilakukan pengujian hubungan pada variabel money attitudes dan financial stress terhadap financial well-being terlebih dahulu. Hasil pengujian ditunjukkan pada Tabel I.

Tabel I.

Hasil uji hubungan antar Money Attitudes, Financial Stress, dan Financial Well-Being

\begin{tabular}{rll}
\hline \multicolumn{1}{c}{ Variabel } & $\mathbf{r}$ & $\mathbf{P}$ \\
\hline Money Attitudes & & \\
a. Power Prestige & $.21^{* *}$ & .000 \\
b. Retention Time & $-.34^{* *}$ & .000 \\
c. Distrust & $.15^{*}$ & .016 \\
d. Anxiety & .11 & .064 \\
Financial Stress & $-.13^{*}$ & .036 \\
\hline
\end{tabular}

Significant:

$\mathrm{p}<0.01,{ }^{*} \mathrm{p}<0.05$

Berdasarkan hasil pengujian uji hubungan yang ditunjukkan di Tabel I, diketahui bahwa terdapat hubungan antara financial well-being dengan power prestige money attitudes $(r=.2 \mathrm{I}, \mathrm{p}<.0 \mathrm{I})$, retention time money attitudes $(r=-.34, p<.01)$, distrust money attitudes $(r=.15, p<.05)$, dan financial stress $(r=-$ $.13, \mathrm{p}<.05)$. Maka berikutnya akan dilakukan pengujian hipotesis seperti yang digambarkan pada Gambar I., yaitu pengujian dengan menggunakan PROCESS HAYES model 4. Pengujian ini adalah kembangan dari Preacher \& Hayes (2008) yang menggambarkan efek tidak langsung pada variabel intervening (dan standard error) dengan menggunakan bootstrapped. Penentuan signifikansi efek tidak langsung dilihat berdasarkan nilai interval kepercayaan, jika interval kepercayaan tidak termasuk nol atau terdapat angka nol, maka pengaruh tidak langsung pada uji ini dinyatakan signifikan. Maka hasil analisis pada penelitian ini menunjukkan bahwa financial stress dapat berperan sebagai mediator antara power prestige money attitudes dengan financial well-being dengan indirect effect $=-.02, \mathrm{se}=.0 \mathrm{I}, \mathrm{Cl}$ $(-.04,-.002)$. Pada retention time money attitudes dengan financial well-being, financial stress tidak dapat berperan sebagai mediator, yaitu indirect effect $=.0 \mathrm{I}$, se $=.02, \mathrm{Cl}(-.02, .05)$. Sedangkan pada distrust 
money attitudes dengan financial well-being, financial stress dapat berperan sebagai mediator dengan indirect effect $=-.02, \mathrm{se}=.0 \mathrm{I}, \mathrm{Cl}(-.04,-.0004)$. Sehingga hipotesis dapat terpenuhi, meskipun tidak semua aspek dari money attitudes dapat berhubungan dengan financial well-being.

\section{Pembahasan}

Temuan yang ditunjukkan dari hasil analisis di atas, diketahui bahwa tiga aspek money attitudes memiliki hubungan dengan financial well-being. Pada power prestige dan distrust memiliki korelasi positif terhadap financial well-being. Hal ini cukup menarik untuk dicermati, dua aspek dari money attitudes menggambarkan uang sebagai simbol kesuksesan yang dapat mempengaruhi orang lain serta adanya kecurigaan atau keragu-raguan saat berada pada kondisi yang melibatkan uang (Chi \& Banerjee, 2013); namun situasi ini bisa dianggap memberikan financial well-being bagi mahasiswa rantau. Berdasarkan penelitian yang dilakukan oleh Cfpb (20I5) diketahui bahwa hal pertama yang dianggap sebagai bagian dari financial well-being bagi individu masa kini adalah mampu mendapatkan "hal yang diinginkan" dalam hidup. Hal inilah yang bisa menjelaskan alasan power prestige dan distrust dapat memiliki korelasi yang positif terhadap financial well-being. Selain itu, sesuai dengan penelitian yang dilakukan oleh Campara, Vieira, \& Potrich (20I7); Elgeka et al. (20 I 8); Khare (20I 5); Sabri \& Zakaria (20I5) yang menyatakan bahwa individu akan merasa bahagia dan sejahtera jika mereka memiliki uang yang banyak dan dapat digunakan sebagai simbol untuk memberikan impression (kesan) pada orang lain. Pada aspek power-prestige money attitudes individu akan memiliki potensi untuk hidup lebih boros atau memiliki sikap materialisme (Rimple, Srikant, Naseem, \& Kumar, 20I5), khususnya pada mahasiswa rantau yang masih pada masa transisi atau waktu untuk beradaptasi dengan situasi yang baru. Pemahaman akan financial well-being yang dimaknai oleh mahasiswa rantau di sini adalah di saat mereka mampu memenuhi segala "keinginannya" atau kebutuhan materinya.

Pada aspek retention time money attitudes menunjukkan adanya korelasi negatif dengan financial wellbeing. Hal ini tentu dirasa cukup mengejutkan, namun jika melihat hasil penelitian yang dilakukan oleh Cfpb (2015) diketahui bahwa menabung adalah urutan keenam dari pandangan individu saat ini. Sehingga keputusan untuk berhemat akan terasa sangat menghalangi individu untuk memenuhisegala kebutuhannya dan itu akan dianggap tidak sejahtera secara keuangan. Hal ini sangat dipahami dan sesuai dengan yang dinyatakan oleh Mishra, Tatzel, Arun, \& Abidi (20I4); Rimple et al. (20I5); Sardžoska \& Tang (20I5) bahwa individu yang memiliki retention time money attitudes akan menabung untuk masa depan dan tidak akan membelanjakan uangnya untuk membeli barang-barang material. Sabri \& Zakaria (20I5) dalam penelitiannya menunjukkan hal yang berbeda dengan temuan yang ada di penelitian ini, pada penelitiannya dikatakan bahwa retention time money attitudes akan berpengaruh positif dengan financial well-being. Hal ini terjadi karena responden pada penelitian mereka adalah para pekerja, dimana para pekerja tentu akan memikirkan masa depan sehingga mereka akan berhatihati dalam mengelola keuangannya. Pada pen elitian ini, respondennya adalah mahasiswa dimanasudut pandang mahasiswa agak berbeda dengan para pekerja, serta alat ukur money attitudes juga diberikan pada mahasiswa (Chi \& Banerjee, 20l3), sehingga cara memandang menabung belum menjadi prioritas utama bagi para mahasiswa.

Financial stress berhubungan negatif dengan financial well-being, hal ini dipahami bahwa saat individu belum mampu mengelola keuangannya dengan baik maka mereka akan mengalami financial stress dan akan membuat financial well-being menjadi menurun. Financial stress ini akan sangat bergantung pada persepsi dari mahasiswa rantau terkait kondisi keuangannya (Mokhtar \& Husniyah, 20 I7; Sabri \& Zakaria, 2015; Vosloo et al., 20I4), sehingga kondisi keuangan itu membuat mereka tidak mampu lagi membeli barang-barang yang "diinginkan". Di kala mahasiswa rantau tidak memiliki uang yang cukup, tentu hal itu akan sangat mempengaruhi produktivitas dari kesehariannya (Sabri \& Zakaria, 20 I5). Apalagi pada penelitian Northern et al. (2010) dijelaskan bahwa saat individu memiliki financial stress nilai akademik serta permasalahan mental akan terpengaruh; sehingga tentu financial well-being tidak dapat diraih.

Berdasarkan uji hipotesis diketahui bahwa financial stress dapat berperan sebagai mediator pada aspek power prestige dan distrust money attitudes dengan financial well-being. Hasil ini menggambarkan bahwa saat mahasiswa rantau mampu memenuhi segala kebutuhan dan "keinginannya" dan 
menjadikan uang sebagai simbol kesuksesan, maka mereka akan merasa sejahtera secara keuangan dan tidak mengalami financial stress. Namun jika hal sebaliknya terjadi, maka financial stress akan muncul dan membuat mereka merasa tidak sejahtera secara keuangan. Seperti yang dijelaskan oleh Sabri \& Zakaria (20I5) bahwa disaat individu mengalami masalah keuangan ataupun kekurangan uang untuk membelanjakan kebutuhannya dan memiliki kemampuan mengelola uang yang buruk tentu akan sangat berpengaruh pada financial stress dan berdampak pada financial well-being. Maka, mahasiswa rantau diharapkan mampu memahami teknik mengelola keuangan yang baik dan memahami makna uang dengan benar, agar mereka tidak terus menerus membelanjakan uang dan jatuh pada compulsive buying ataupun materialisme (Mishra et al., 20 I4; Rimple et al., 20 I5).

\section{Kesimpulan}

Penelitian ini ingin menjelaskan penyebab terbentuknya financial well-being pada mahasiswa rantau di Surabaya. Berdasarkan hasil pengujian dengan PROCESS HAYES diketahui ada beberapa hal yang mendukung terbentuknya financial well-being, sehingga dapat dibuat beberapa kesimpulan. Pertama, power-prestige dan distrust pada money attitude membuat mahasiswa rantau merasakan kesejahteraan secara keuangan disaat mereka mampu memberikan kesan pada orang lain dan mampu memenuhi segala "keinginan" atau kebutuhan materinya. Sehingga situasi ini harus diwaspadai, jika tidak berhatihati dalam penggunaan uang, tentu mahasiswa rantau akan jatuh kepada financial hardship. Kedua, pada aspek retention-time, mahasiswa rantau justru tidak merasa bahagia dan sejahtera secara keuangan. Menabung bagi mahasiswa rantau ternyata belum menjadi prioritas utama, meskipun di survey awal diketahui bahwa mereka ada ketakutan pada masa depan. Namun, ternyata hal tersebut belum sepenuhnya dipikirkan pada kondisi saat ini, orientasi mereka masih memenuhi kebutuhan sekarang. Ketiga dan yang terakhir, financial stress akan berdampak negatif pada financial well-being, dimana mahasiswa rantau akan kehilangan konsentrasi saat belajar dan mengalami gangguan kesehatan baik secara fisik ataupun mental. Di saat mahasiswa rantu mengalami financial stress mereka akan memiliki kemungkinan untuk menyalahkan pihak lain atas kondisinya.

Melalui hasil penelitian ini diharapkan dapat memberikan manfaat pada para mahasiswa khususnya mahasiswa rantau yang ada di Indonesia. Setiap mahasiswa rantau diajak untuk mulai bisa menata dan mengelola keuangannya dengan baik agar mendapatkan financial well-being. Gaya hidup konsumutf hendaknya mulai dihindari agar tidak menimbulkan financial hardship di masa yang akan datang dan memberikan penyesalan. Keterbatasan pada penelitian ini adalah jumlah responden yang hanya difokuskan di Surabaya membuat penelitian ini belum mampu digeneralisasikan lebih luas lagi. Sehingga pada penelitian selanjutnya diharapkan dapat mengambil subjek dengan jangkauan yanglebih luas, misalkan dengan mengambil responden di 5 kota besar (Jakarta, Bandung, Surabaya, Medan, dan Makassar) di Indonesia. Selain itu, pada penelitian berikutnya disarankan agar alat ukur financial stress dapat menggunakan alat ukur yang difokuskan pada mahasiswa dan memiliki karakteristik yang mirip dengan di Indonesia.

\section{REFERENSI}

Akben-Selcuk, E. (20 I5). Factors influencing college students' financial behaviors in Turkey:Evidence from a national survey. International Journal of Economics and Finance, 7(6), 87-94.

Doi: 10.5539/ijef.v7n6p87

Beutler, I. F., \& Gudmunson, C. G. (20I2). New adolescent money attitude scales : Entitlement and conscientiousness. Association for Financial Counseling and Planning Education, 23(2), 18-31.

Campara, J. P., Vieira, K. M., \& Potrich, A. C. G. (2017). Overall life satisfaction and financial wellbeing: Revealing the perceptions of the beneficiaries of the bolsa familia program. Revista de Administração Pública, 5 I (2), |82-200. Doi: 10.1590/0034-76I2I56I68

Cfpb, C. F. P. B. (20I5). Financial well-being: The goal of financial education. Retrieved from https:/www.consumerfinance.gov/data-research/research-reports/financial-well-being/ 
Chi, Y. N., \& Banerjee, G. (20I3). Empirical analysis of bicultural border college students' attitudes toward money. Journal of Applied Business and Economics, I 4(3), 70-82.

Collins, J. M., \& Urban, C. (2020). Measuring financial well-being over the lifecourse. Europeanjournal of Finance, 26(4-5), 34 I-359. Doi: I0.1080/I35 I847X.20 I9.168263 I

Donnelly, G., lyer, R., \& Howell, R. T. (2012). The big five personality traits, material values, and financial well-being of self-described money managers. Journal of Economic Psychology, 33(6), I I 29-I | 42. Doi: I0.10 I6/j.joep.2012.08.00 I

Elgeka, H. W. S., Ma, J., Secapramana, L. V. H., \& Yudiarso, A. (2019). Money attitude and conscientiousness influence mental budgeting: A comparative study between Indonesia and China. Psychologia, 6I(I), 26-36. Doi: 10.21 I7/psysoc.2019-A004

Guven, C. (2012). Reversing the question: Does happiness affect consumption and savings behavior? q. Journal of Economic Psychology, 33(4), 70 I-7 I 7. Doi: I 0.I 0 I6/j.joep.20I 2.01 I.002

Hayhoe, C. R., Cho, S. H., Devaney, S. A., Worthy, S. L., Kim, J., \& Gorham, E. (20I2). How do distrust and anxiety affect saving behavior? Family and Consumer Sciences Research Journal,4I(I), 69-85. Doi: I0.I I I I/j.I552-3934.20I2.02I29.x

Herlindawati, D. (20I5). Pengaruh kontrol diri, jenis kelamin, dan pendapatan terhadap pengelolaan keuangan pribadi mahasiswa pascasarjana Universitas Negeri Surabaya. Journal Ekonomi Pendidikan Dan Kewirausahaan, 3(1), I 58-169.

Joo, S. (2008). Personal financial wellness. In Handbook of Consumer Finance Research (pp. 2I-33).

Khare, A. (2015). Influence of materialism and money attitudes on credit card use. International Journal of Business Competition and Growth, 4(I/2), 57. https://doi.org/I 0.I 504/ijbcg.20 I 5.070665

Kowalczyk, A., \& Chudzian, J. (20I5). Money attitudes vs economic socialization in Poland. Review of Agricultural and Applied Economics, I8(0I), II-18. Doi: 10.154 I4/raae.2015.18.0 I.I I - 8

Mishra, J. K., Tatzel, M., Arun, B. K., \& Abidi, N. (20I4). Money attitudes as predictors of materialism and compulsive buying, and gender demographics, in the "new India." Int. J. Indian Culture and Business Management, 9(3), 30I-3 I 5. Doi: I 0.I504/IJICBM.20I4.064695

Mokhtar, N., \& Husniyah, A. R. (2017). Determinants of financial well-being among public employees in Putrajaya, Malaysia. Pertanika Journal Social Sciences \& Humanities, 25(3), I 24I-1 260.

Nidar, S. R., \& Bestari, S. (20I2). Personal Financial Literacy Among University Students (CaseStudy at Padjadjaran University Students, Bandung, Indonesia). World Journal of Social Sciences, 2(4), |62-17|.

Northern, J.J., O'Brien, W. H., \& Goetz, P.W. (2010). The development, evaluation, and validation of a financial stress scale for undergraduate students. Journal of College Student Development, 5 I (I), 79-92. Doi: I0.1353/csd.0.0108

Pappang, R., \& Anastasia, N. (2019). The impact of perceived financial literacy and parental norm towards money management of bidikmisi student. Petra International Journal of Business Studies, 2(2), 7 I-77. Doi: I0.9744/ijbs.2.2.7 I-77

PDDIKTI. (20 18, December). Statistik Pendidikan Tinggi Tahun 2018. Kementerian Riset Teknologidan Pendidikan Tinggi. Retrived from: https://pddikti.kemdikbud.go.id/asset/data/publikasi/Statistik\%20Pendidikan\%20Tinggi\%20lndo nesia\%2020 18.pdf on September 12, 2020.

Prabowo, A. (2019). Siaran Pers. Survei OJK 2019: Indeks literasi dan inklusi keuangan meningkat. Retrieved from: https://www.ojk.go.id/id/berita-dan-kegiatan/siaran-pers/Pages/Siaran-PersSurvei-OJK-20 I 9-Indeks-Literasi-Dan-Inklusi-Keuangan-Meningkat.aspx on September I2, 2020.

Preacher, K. J., \& Hayes, A. F. (2008). Asymptotic and resampling strategies for assessing and comparing indirect effects in multiple mediator models. Behavior Research Methods, 40(3),87989I. Doi: 10.3758/BRM.40.3.879

Rasyid, R. (20I2). Analisis tingkat literasi keuangan mahasiswa program studi manajemen Fakultas Ekonomi Universitas Negeri Padang. Jurnal Kajian Manajemen Bisnis, I (2), 9I-I06.

Rimple, M., Srikant, M., Naseem, A., \& Kumar, M. J. (20I5). A study of interaction of materialism and money attitude and its impact on car purchase. Management \& Marketing. Challenges for the Knowledge Society, 10(3), 245-269. Doi: I0.15 I5/mmcks-20 I 5-00 I 7.Introduction 
Sabri, M. F., \& Zakaria, N. F. (20I5). The influence of financial literacy, money attitude, financial strain and financial capability on young employees' financial well-being. Pertanika Journal Social Sciences \& Humanities, 23(4), 827-848.

Sardžoska, E. G., \& Tang, T. L. P. (2015). Monetary intelligence: Money attitudes-unethical intentions, intrinsic and extrinsic job satisfaction, and coping strategies across public and private sectors in Macedonia. Journal of Business Ethics, I 30(I), 93-I I 5. Doi: I0.1 007/s I 055 I0|4-2।97-5

Shim, S., Barber, B. L., Card, N. A., Xiao, J. J., \& Serido, J. (2010). Financial socialization of first-year college students: The roles of parents, work, and education. Journal of Youth and Adolescence, 39(12), 1457-1470. Doi: 10.1007/s 10964-009-9432-x

Sina, P. G., \& Raturomon, L. T. (20I5). Analisis stres finansial pada gender. Jurnal Ekonomi Dan Pendidikan, 9(I), I02-I I 2. Doi: I0.2 I83 I/jep.v9il.4I57

Strömbäck, C., Lind, T., Skagerlund, K., Västfjäll, D., \& Tinghög, G. (20I 7). Does self-control predict financial behavior and financial well-being? Journal of Behavioral and Experimental Finance, I4,3038. Doi: 10.1016/j.jbef.2017.04.002

von Stumm, S., Fenton O'Creevy, M., \& Furnham, A. (20I3). Financial capability, money attitudes and socioeconomic status: Risks for experiencing adverse financial events. Personality and Individual Differences, 54(3), 344-349. Doi: I0.10 I6/j.paid.20I 2.09 .019

Vosloo, W., Fouche, J., \& Barnard, J. (20I4). The relationship between financial efficacy, satisfaction with remuneration and personal financial well-being. International Business \& EconomicsResearch Journal (IBER), I3(6), I 455. Doi: I0.19030/iber.v I 3i6.8934

Wulandari, \& Hakim, L. (20I5). Pengaruh love of money, pendidikan keuangan di keluarga, hasil belajar manajemen keuangan, dan teman sebaya terhadap manajemen keuangan pribadi Mahasiswa. Jurnal Pendidikan Akuntansi, 3(3), I-6.

Yamauchi, K. T., \& Templer, D. I. (1982). The development of a money attitude scale. Journal of Personality Assessment, 46(5), 522-528.

Yolanda, A., \& Rembulan, C. L. (20I7). Hubungan antara impulse buying dengan financial well-being pada wanita early career. Psychopreneur lournal, I(I), 20-34. Retrieved from https://journal.uc.ac.id/index.php/psy/article/view/356 